\title{
Redo Bentall's Procedure for Annuloaortic Ectasia with Severe Aortic Regurgitation: A Video Presentation
}

\author{
Lakshmi Kumari Sankhyan ${ }^{1} \quad$ Ujjwal K. Chowdhury ${ }^{1} \quad$ Niwin George ${ }^{1} \quad$ Sukhjeet Singh ${ }^{1} \quad$ Vasubabu Gudala ${ }^{1}$ \\ Sushma Gayatri B ${ }^{1}$ Poonam Malhotra Kapoor ${ }^{2}$
}

${ }^{1}$ Department of Cardiothoracic and Vascular Surgery, All India Institute of Medical Sciences, New Delhi, India

${ }^{2}$ Department of Cardiac Anaesthesia, All India Institute of Medical Sciences, New Delhi, India

\begin{abstract}
Address for correspondence Ujjwal K. Chowdhury, MCh, Diplomate NB, Department of Cardiothoracic and Vascular Surgery, All India Institute of Medical Sciences, New Delhi 110029, India

(e-mail: ujjwalchowdhury@rediffmail.com; ujjwalchowdhury@gmail.com).
\end{abstract}

J Card Crit Care TSS 2020;3:39-41
Abstract
Keywords
- annuloaortic ectasia
- Redo Bentall's
procedure
- severe aortic
regurgitation

A 25-year old female patient with repaired ventricular septal defect and aortic valvular reconstruction underwent successful aortic root replacement using a composite graft with mechanical valve.

\section{Introduction}

Despite introduction of several technical modifications into the "open button technique", bleeding from the graft-coronary anatomoses and proximal aortic conduit suture line and coronary ostial aneurysm continue to occur because of fragility and reduced tissue quality of the ascending aortic wall. ${ }^{1-4}$

We present here-in two technical modifications of the "open button technique and proximal aortic conduit suturing" in a 25-year-old female patient with repaired ventricular septal defect and aortic valvular reconstruction undergoing aortic root replacement for annuloaortic ectasia.

We interposed a glutaraldehyde-treated autologous pericardial strip between the graft and native coronary ostia during coronary ostial implantation and placed interrupted, interlocking aortic annular pledgeted mattress sutures to ensure perfect hemostasis at the suture lines ( $\mathbf{- F i g . ~ 1 A - F ) . ~}$

Postoperative course was uneventful with $180 \mathrm{ml}$ drainage in the first 24-hours. Postoperative computerized tomographic angiography revealed widely patent coronary arteries, intact proximal and distal anastomoses with no pseudoaneurysm formation at the anastomotic sites (-Fig. 2).

\section{Surgical Techniques}

1. Elective right femoral arteriovenous cannulation using long femoral arterial and venous cannulae (Edwards Lifesciences LLC, One Edwards Way, Irvine, California) following systemic heparinization (-Video 1).

2. Under cardiopulmonary bypass, primary median sternotomy is performed and a rectangular segment of pericardium is harvested and fixed in glutaraldehyde for 10 minutes for later use during coronary button implantation.

3. The main pulmonary artery is vented for further decompression of the heart to facilitate dissection.

4. The cardiac chambers and great vessels are freed of adhesions using cautery dissection at 15 to $20 \mathrm{mV}$.

5. The superior vena cava is dissected and cannulated directly using an angled metal tipped venous cannula and drained directly into the oxygenator.

6. A pursestring suture is placed using 5-O polypropylene at the medial aspect of the inferior vena cavaright atrial junction and a retrograde coronary sinus cannula (Medtronic Inc., Minneapolis, Minnesota) is inserted taking care not to damage the wall of the published online

November 05, 2019
DOI https://doi.org/

$10.1055 / \mathrm{s}-0039-1697685$ ISSN 2457-0206.
Copyright @2020 Official Publication of The Simulation

Society (TSS), accredited

by International Society of Cardiovascular Ultrasound (ISCU).
License terms

(이 (1) $\Theta \circledast$ 

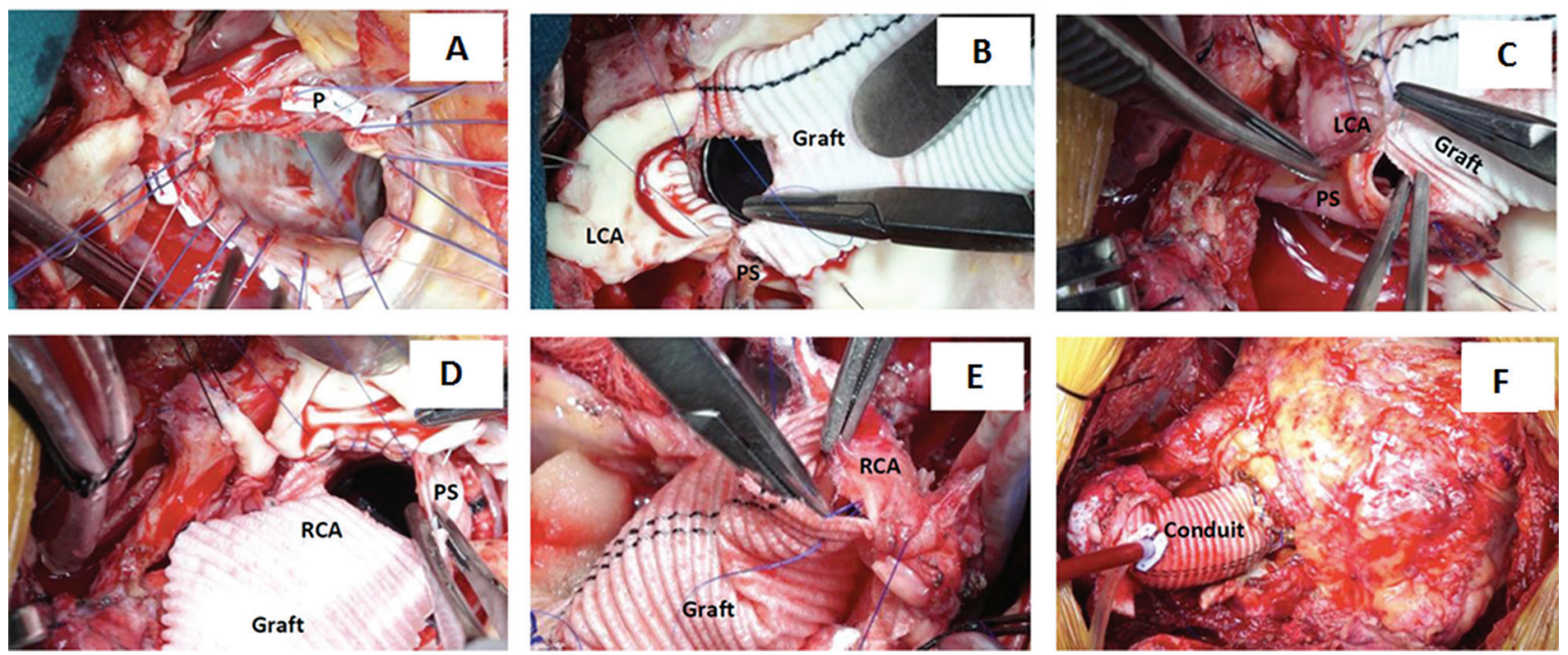

Fig. 1 (A-F) Surgical photograph of the techniques used for coronary button implantation and proximal aortic conduit suturing in the patient undergoing redo Bentall's procedure for annuloaortic ectasia. Note the placement of interlocking, interrupted, pledgeted mattress sutures ensuring perfect hemostasis. Note the circumferential placement of the pericardial strip between the graft and the native coronary ostia. LCA, left coronary artery; P, pledget; PS, pericardial strip; RCA, right coronary artery.

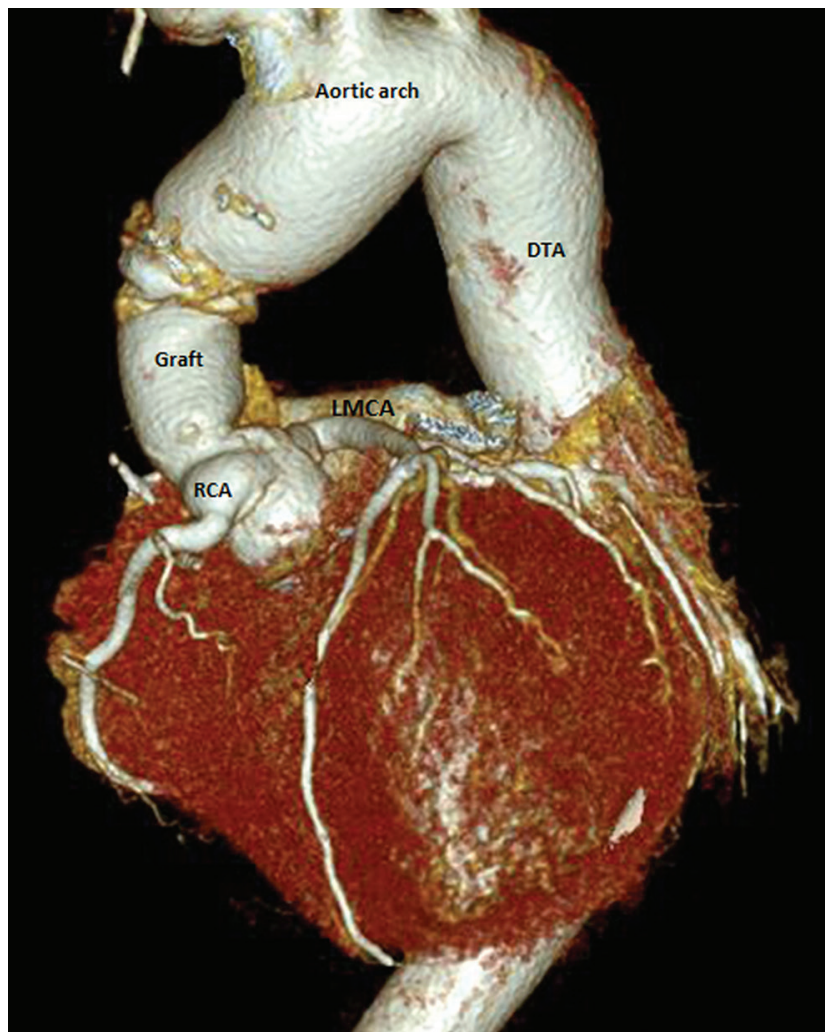

Fig. 2 Postoperative computerized volume rendered image revealed widely patent left and right coronary arterial systems, intact proximal and distal anastomoses. DTA, descending thoracic aorta; LMCA, left main coronary artery; RCA, right coronary artery.

\section{Video 1}

Redo Bentall's procedure for annuloaortic ectasia. Online content including video sequences viewable at: www. thieme-connect.com/products/ejournals/html/ $10.1055 / \mathrm{s}-0039-1697685$. coronary sinus and its tributaries using finger manipulation and transesophageal echocardiographic guidance ensuring that the tip of the coronary sinus cannula lies at the base of the left atrial appendage.

7. The right superior pulmonary vein is vented on a partially filled heart avoiding intracardiac air suction.

8. The ascending aorta is dissected free from the main pulmonary artery and right pulmonary artery for later selective aortic cross-clamp.

9. The aorta is cross-clamped using an atraumatic aortic vascular clamp and aortotomy is being done in between stay sutures (-Video 1).

10. Myocardial protection is achieved by integrated myocardial protection and topical cardiac cooling using ice cold saline.

11. The left and right coronary buttons are harvested, leaving behind 10 to $12 \mathrm{~mm}$ of the excised aortic wall around the coronary ostia.

12. Three stay sutures are placed on the three commissures of the aortic valve and the aortic valve is excised leaving behind a rim of the aortic leaflet.

13. Note the placement of everted, interrupted 2-O mattress sutures over polytetrafluoroethylene pledgets (Ethicon, Cincinnati, Ohio) for proximal aortic conduit suture line. Each interrupted pledgeted mattress suture is passed through the previous pledget, thus ensuring perfect aortic annular hemostasis.

14. An appropriate sized aortic valve sizer is inserted through the aortic opening for sizing of the composite aortic conduit.

15. A 21-mm Dacron composite graft with a mechanical valve (St. Jude Medical Inc., St. Paul, Minnesota) is placed and the sutures are tied.

16. Using graft cautery, two side holes are created on the composite conduit graft measuring around $10 \mathrm{~mm}$ in diameter in the proposed area of implantation of left and right coronary ostia, respectively. 
17. Step-by-step demonstration of the left and right coronary button anastomosis. Note the circumferential placement of the pericardial patch between the graft and the native coronary ostium using 5-O polypropylene suture.

18. The cardioplegic solution is administered through an inflated $16 \mathrm{~F}$ Foley catheter inserted through the graft opening for checking hemostasis of the aortic root and coronary button anastomoses.

19. At this stage we used topical thrombin (Tisseel, Baxter AG, Vienna, Austria) as an additional topical hemostatic agent.

20. The distal graft-aortic anastomosis is performed using 4-O polypropylene suture in an end-to-end fashion by interposition technique. Two Teflon strips are being placed both intraluminally within the aorta and externally to ensure perfect hemostasis.

21. A root cardioplegia cannula is inserted to facilitate cardiac de-airing on release of aorticcross-clamp (-Video 1).

\section{Conclusions}

We conclude that interposition of a pericardial strip as a buttressing material between the graft-coronary anastomoses reinforces the suture line avoiding cut through and perianastomotic excessive fibrous tissue reaction. The interrupted, pledgeted, interlocking aortic annular suturing is an expedient, safe and effective technique of obtaining perfect hemostasis.

\section{Conflict of Interest}

None.

\section{References}

1 Copeland JG III, Rosado LJ, Snyder SL. New technique for improving hemostasis in aortic root replacement with composite graft. Ann Thorac Surg 1993;55(4):1027-1029

2 Nezic D, Cirkovic M, Knezevic A, Jovic M. Modified Bentall procedure - 'a collar technique' to control bleeding from coronary ostia anastomoses. Interact Cardiovasc Thorac Surg 2008;7 (4):709-711

3 Milano AD, Pratali S, Mecozzi G, et al. Fate of coronary ostial anastomoses after the modified Bentall procedure. Ann Thorac Surg 2003;75(6):1797-1801

4 Sokullu O, Sanioglu S, Orhan G, et al. New use of Teflon to reduce bleeding in modified Bentall operation. Text Heart Inst J. 2008;35(2):147-151 